\title{
Evaluation framework for urban development programs: the case of Morocco
}

\author{
Saida Hajjaji ${ }^{1}$, Mounir Zouiten ${ }^{2}$ \\ ${ }^{1}$ Mohammed V University, Rabat, Morocco \\ ${ }^{2}$ Mohammed V University, Rabat, Morocco
}

\begin{abstract}
The evaluation of urban development programs is now a prerequisite for any initiative to improve their effectiveness. The United Nations has designated 2015 as the International Year of Evaluation (EvalYear). This global initiative aims to support the development of an enabling environment for evaluation at international, national, and local levels (UN, 2015). In Morocco, the situation is still characterized by a weak anchoring of the evaluation function in the political-institutional landscape, except for a few sectoral mechanisms for collecting information and drawing up diagnoses. However, there is a real awareness of this, as the new Constitution of 2011 addresses this deficit and highlights the importance of evaluation in the management of public affairs. In this context, the Moroccan Ministry of Housing has initiated several evaluation studies on specific programs. Accordingly, we will analyze three evaluation studies of urban development projects. The objective of our work is to verify to what extent the modeling of the program evaluation process, developed by Hurteau and Houle (2006), was applied to the evaluation reports analyzed and to issue a wellfounded judgment. To do this, we translated the steps of modeling the evaluation process into indicators to create an analysis grid. However, our study may have a limitation in that while the reports analyzed have the advantage of being almost uniform in terms of content, this choice is biased because it does not provide an exhaustive representation of evaluation practice. Finally, the results of our study show that the practice of modeling the evaluation process is not uniform and that it would be important to develop and frame the practice of program evaluation.
\end{abstract}

Keywords: Evaluation-Urban development program, Modeling the evaluation process.

\section{INTRODUCTION}

Given the importance of the housing sector in the various economic and social development plans (19602004). The issue of housing in general and social housing in particular, has been a major concern of the public authorities in Morocco since the country's independence. To eradicate the various forms of slum housing on the one hand and promote housing for low-income households on the other, several large-scale programs were designed and implemented over the past decades.

Since 1995, the country and particularly the housing sector have known four schemes promoting social housing, namely:

- The national 200,000 housing scheme;

- The system of housing with a total property value of between DH 80,000 and 120,000, covering the five years 2003-2007 and aiming to achieve 100,000 housing units per year;

- The housing scheme with a low total property value of 140,000 DH covering the five years 2008-2012 and aiming to generate 130,000 housing units; 
- The scheme for the decade 2010-2020 aiming to produce a new type of housing whose total property value does not exceed 250,000 DH excluding taxes and aiming to generate 300,000 housing units during this period.

These four schemes have benefited from several advantages and privileges related to taxation, financing, land, the instruction of files, and the exemption in terms of zoning, etc. In addition, significant efforts were made to supervise and complete all these programs during all these periods.

At the same time, the Ministry of supervision held several meetings, both at the national and regional levels, with the various actors who were interested in the housing sector and in particular in social housing. The objective is the establishment of a spirit of understanding and mutual support to create the appropriate conditions for the success of these schemes that were initiated by the High Royal Directives.

Moreover, despite the weak anchoring of the evaluation function in Morocco (Aboulaaguig, 2015), the Ministry of Housing, Urban Planning and Urban Policy has been committed for several decades to an evaluation approach for public actions, to improve the efficiency of public aid granted to the housing sector in the form of direct aid and/or tax exemptions. Among the Ministry's latest achievements in this area, we note the study on the evaluation of the social housing program at DH 250,000 and the program for low-value housing at DH 140,000 (Ministry of Housing, Urban Planning and Urban Policy, 2018). Therefore, this study consists of analyzing three evaluation studies on urban development projects, according to the model of Hurteau and Houle (2006). These studies are as follows: First, the study on the analysis of the social impact and poverty of the program of cities without slums (Report 1), conducted in 2006 in partnership between Morocco and the World Bank. Second, the study on the evaluation of the program of social housing at 250,000 DH and the program of housing with a low real estate value of 140,000 DH (Report 2), completed in 2017; and third, the study on the evaluation of the program of 200,000 social housing units, conducted in 2007 (Report 3). The minister in charge initiated these last two studies.

\section{LITERATURE REVIEW:}

\section{A. Evaluation practices:}

The concept of evaluation has been in vogue in recent years all around the world. Given the evolution of democratic modes of governance of public affairs, it has emerged as soon as public policies are no longer expressed in abstract terms and unquantifiable objectives, but in terms of results to be achieved within fixed periods, based on identified and available resources and means.

According to a commonly accepted definition, the purpose of public policy and program evaluation is to assess the value-added to society (BASLÉ et al., 2018).

In other words, to measure the effectiveness of public policies by comparing their results with the objectives set and the means implemented. Thus, the evaluation mechanism attempts to examine the performance of public intervention in terms of relevance, effectiveness, efficiency, and coherence (BASLÉ et al., 2018). Evaluation is important because of the relevance of the questions it seeks to answer and the interest of the lessons it gives rise to, for the improvement of future interventions. As a result, evaluation is a good means of learning, capitalizing on good practices. Besides, it allows for the continuous improvement of the decision-making process.

However, beyond the apparent simplicity of this definition, the requirement to evaluate often comes up against the vague or contradictory objectives of public action, the difficulty of measuring its results, and the reluctance of public authorities to submit to it. Moreover, although the practice of evaluation includes 
observation, measurement, and analysis techniques, it is not limited to them. Indeed, it is first an institutional activity that is intended to be integrated into public management and an approach based on a series of values (rigor, impartiality, transparency, etc.).

Several institutions and bodies are concerned by the evaluation. However, the central administrations are at the forefront of the entities in charge of evaluation due to their prerogatives in designing and implementing public policies or sectoral action programs.

Thus, at a time of new public management requirements, the evaluation of public policies is unavoidable. However, it must be noted that the question of its real development and its concrete repercussions must be considered with caution. This is all the more true because the boundaries that distinguish it from other feedback practices (monitoring, management control, benchmarking, auditing, etc.) are difficult to draw and because evaluation itself is diverse, both in terms of its aims and methods and in terms of the type of object submitted for examination (Mongiat, 2007).

Indeed, policies are evaluated, but also regulatory measures, projects, the activity of public institutions and organizations, in other words, public action as a whole.

At the level of implementation, the evaluation must obey a rigorous scientific approach that touches on several areas of specialization (BASLÉ et al., 2018); it is therefore in essence multidisciplinary. As mentioned above, the practices of this concept highlight six simple criteria to help the sponsor and the evaluator identify the main 'qualities' of a 'good' public policy:

- Coherence in design and implementation: are the different objectives coherent with each other? Are the legal, human, and financial resources put in place appropriate to these objectives?

- Achievement of objectives: how closely do the observed changes in social reality match the policy objectives?

- Effectiveness: how well do the policy's effects match its objectives?

- Efficiency: How well were the financial resources used for the policy? What are the benefits of the costs incurred?

- Impact: What are the overall consequences of the policy for society? Are these consequences beneficial?

- Relevance: are the stated objectives in line with the problems to be solved? A policy is very generally justified by the identification of a "societal problem" that the public authorities feel obliged to address. A policy will thus be said to be relevant if its explicit objectives are adapted to the nature of the problem(s) it is supposed to solve or address.

There are many evaluation methods, but three criteria distinguish these methods. These criteria are time, methods, and actors \& beneficiaries.

- The first temporal criterion consists in distinguishing between an ex-ante, extempore, or ex-post evaluation (BOUTAUD, 2015):

- Ex-ante evaluation, which concerns evaluations before the decision or program to be implemented;

- Extempore evaluation or concomitant evaluation is carried out as the public action progresses. This form of evaluation allows, in particular, to help the actors to improve their knowledge of the effects of their intervention to better adjust it to the objectives they have assigned to the project; 
- Ex-post evaluation, which takes place after the action has been carried out.

- Three evaluation methods can be distinguished:

- Comparative evaluation, which aims above all to identify the changes produced by the implementation of the action on a population or a situation. It makes it possible to assess the extent to which the objectives assigned to the action have been effectively achieved and to see whether other effects than those hoped for have been obtained, including unexpected effects. (Vartiainen, 2013)

- Analytical evaluation is relevant when the client wants to know the processes involved in carrying out an action or implementing a service. It is particularly useful when it seems inappropriate to dissociate the results of a program from the conditions of its implementation;

- Dynamic evaluation, which has a clear operational purpose: to use the results of the analysis to modify the action as it progresses and adapts the organization accordingly. By referring to the objectives assigned to this evaluation study, we can see that the purposes of these three types of evaluation, classified according to the function criterion, meet these objectives perfectly.

- Actors and beneficiaries of the evaluation: Any program involves two categories of beneficiaries (Boulmetis \& Dutwin, 2005):

- Formative evaluation, which focuses on informing the protagonists of the program to modify their behavior, improve the action and, if necessary, transform its very purpose;

- Summative evaluation is intended to allow outsiders (government, elected officials, the public) to form an overall opinion of the value of the project.

\section{B. Program evaluation}

Although it has been practiced since antiquity, the practice of evaluation began to flourish in the early 1960s in Anglo-Saxon countries (Mongiat, 2007). The practice then spread to various countries under the influence of international institutions (World Bank, International Monetary Fund, OECD, etc.).

While program evaluation initially focused primarily on assessing the effects of a program in quantitative terms, this field has gradually become interested in the different aspects of a program by deploying a variety of approaches to make credible value judgments to improve program orientations (Mongiat, 2007).

In France, the evaluation of public policies, when it appeared in the 1980s, represented a real hope: it was announced as the solution that would make up for the imperfections of public management and the lack of democracy in decision making. It was supposed to improve the judgments made about the effects of actions undertaken by public authorities. The definition given in the January 1990 decree emphasizes the measurement of effects: "evaluating public policies consists of measuring the effects they generate and seeking to determine whether the legal, administrative and financial resources implemented produce the effects expected of them.

In Morocco, the situation is still characterized by a weak anchoring of the evaluation function in the politicalinstitutional landscape, except for a few sectoral mechanisms for collecting information and developing sectoral diagnoses (Aboulaaguig, 2015). However, it is reasonable to think that the situation could quickly improve in this regard. Indeed, introduced and cited nine times in the new Constitution of 2011, evaluation appears to be 
one of the key themes on which the state is focusing its ambitions to renew the management of public affairs. This orientation is reinforced by the growing interest of civil society in anchoring this practice in the management of public affairs in line with the requirements of advanced regionalization. As an example of public sectors that have initiated more or less successful experiments in evaluation, the Department of Housing and Urban Planning is in a good position. In fact, since the mid-1990s, this department has launched specific studies with an evaluation component.

\section{Modeling the specific process of program evaluation :}

Despite the proven relevance of social program evaluation and its widespread adoption in different countries, evaluation as currently developed does not allow for a value judgment that takes into account the full complexity of social programs (Sandahl, 2002). According to Guba (1972) in his article entitled The Failure of Educational Evaluation, this limitation is due to the difficulty experienced by evaluators in identifying the specificity of the program evaluation approach (Mongiat, 2007). Scriven (1995) adds to the above that this difficulty is linked to a structural problem related in particular to the construction of judgment and the formulation of recommendations.

The development of program evaluation has taken place thanks to the introduction of normative and descriptive theoretical positioning. While normative theory positioning dictates how evaluators should conduct evaluations, descriptive theory positioning attempts to understand the nature of the different operations and their interrelationships (Christie, 2003).

Descriptive theory positioning is more appropriate for program evaluation (Mongiat, 2007). Seriven (1980) was the first author to address this distinction, which he put forward in his conception of evaluation, which he called the logic of evaluation (Mathison, 2004). Several authors have pursued this line of thought, including Hurteau (1991), Fournier (1995), Stake (2004), and Arens (2006), and have adapted it to the context of a program evaluation. Hurteau and Houle (2006) synthesized these different descriptive theories to create a process model specific to program evaluation. This model is illustrated in Fig. 1.

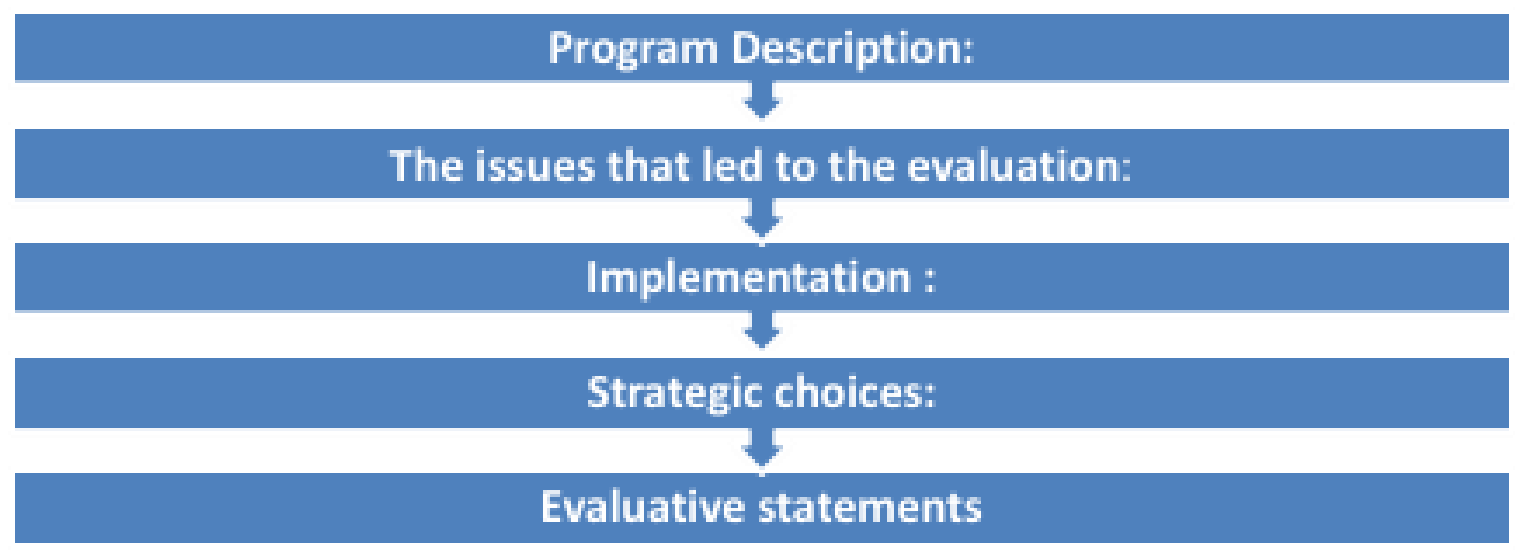

Figure 1. Modeling the specific process of program evaluation (Hurteau \& Houle, 2006)

The first component of this process is the program description. It involves ensuring that there is a program being evaluated and understanding its context and components. In his book Practical Program Evaluation: Assessing and Improving Planning, Implementation, and Effectiveness, Chen (2015) defines a program as a system composed of a set of resources (human, material, and financial) and means (interventions, activities) called inputs. It is implemented within a process interacting with its environment to achieve objectives related 
to the improvement of the target population's well-being, the results of which report on the degree of transformation achieved. Fig. 2 illustrates Chen's definition (2005).

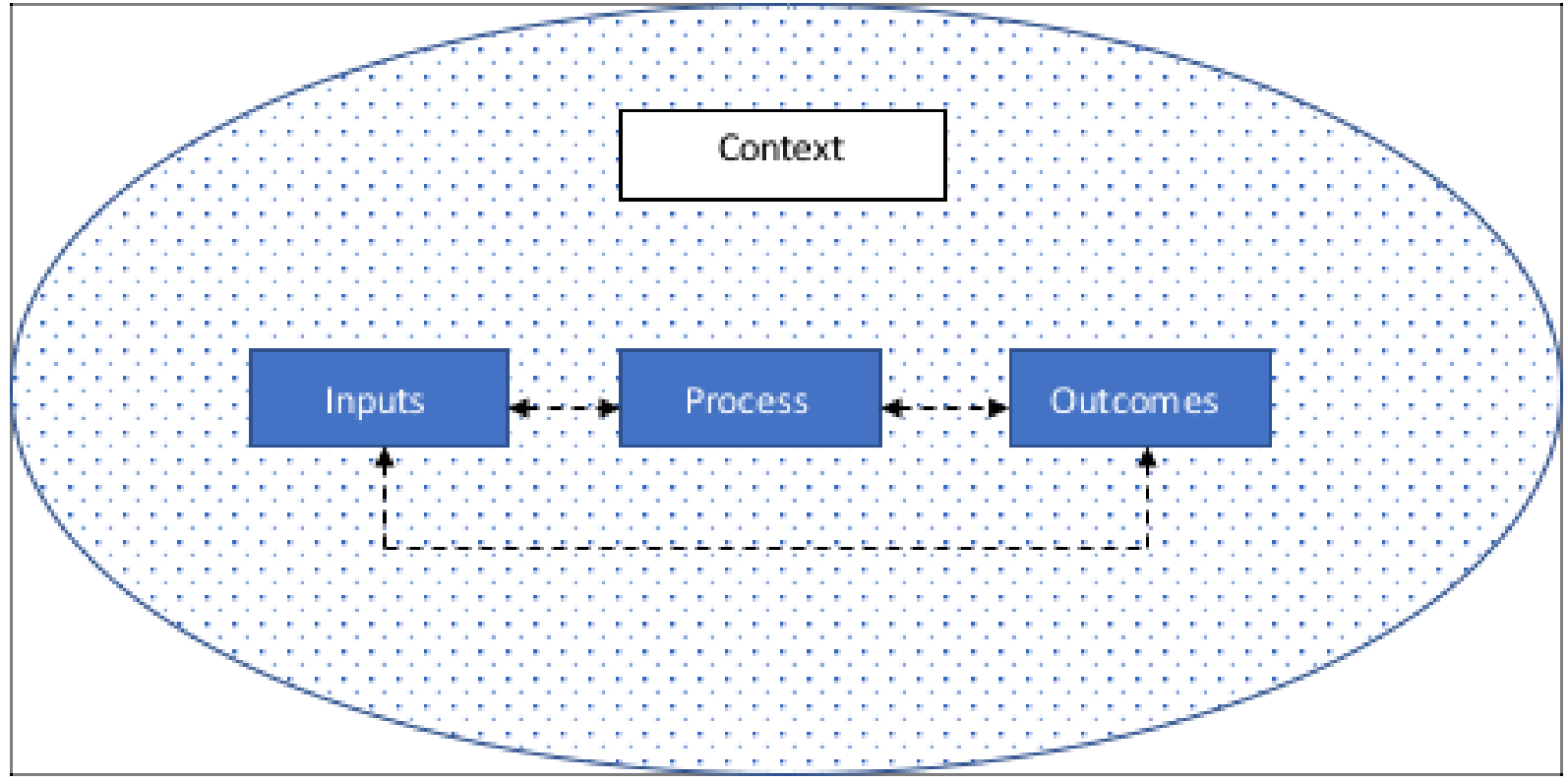

Figure 2. Program: System (Chen \& Chen, 2005)

The second component concerns the evaluation issue. This step is crucial to the evaluation process because it includes the trigger for the evaluation and the concerns of the evaluation's clients.

The third component, operationalizing the evaluation, translates the needs of the problem into program evaluation language to structure the process in terms of questions, objectives, and type of evaluation. To this end, Rossi, Lipsey, and Freeman (2004) identify several types of evaluation (Rossi et al., 2004)

- Needs assessment, consists of identifying the needs of the target population;

- Assessment of program theory attempts to establish which service would meet the identified need;

- Assessment of program process refers to the evaluation of the implementation of the program;

- Impact assessment aims to identify whether the program is achieving its objectives;

- Efficiency assessment aims to identify whether the program could achieve its objectives at a lower cost.

The fourth component, which deals with the strategic choices of the evaluation, is the cornerstone of the evaluation process since it initiates the identification of criteria and standards that are essential for making a sound judgment about the program.

The evaluative statements are based on the analysis of the gaps between the measurement of observable variables and the respective standards.

The last step is to make evaluative conclusions. In other words, it consists of making a substantiated judgment (Mongiat, 2007). 


\section{RESEARCH METHODOLOGY}

Our approach consists of analyzing three urban development program evaluation study reports, according to the model cited above by (Hurteau \& Houle, 2006). The objective of our work is to verify to what extent the modeling of the process specific to the evaluation of the program was applied in the evaluation reports analyzed, to make a well-founded judgment. We have translated the steps of the evaluation modeling process into indicators to create an analysis grid, illustrated in Table I.

TABLE I. ANALYSIS GRID: INDICATORS

\begin{tabular}{|l|l|}
\hline \multicolumn{1}{|c|}{ Process components } & \multicolumn{1}{c|}{ Indicators } \\
\hline Program description & $\begin{array}{l}\text { The program's target population } \\
\text { Program objectives } \\
\text { The characteristics of the intervention } \\
\text { The theoretical framework on which the intervention is based }\end{array}$ \\
\hline Evaluation issue & $\begin{array}{l}\text { The trigger for the evaluation } \\
\text { The type of judgment expected by the beneficiaries } \\
\text { The type of argumentation expected by the beneficiaries }\end{array}$ \\
\hline Evaluation implementation & $\begin{array}{l}\text { Evaluation questions and/or objectives } \\
\text { Types of evaluation (Following the typology of Rossi, Lipsey, Freeman (2004)) } \\
\text { Respect for the type of judgment expected by the beneficiaries }\end{array}$ \\
\hline Strategic choices & $\begin{array}{l}\text { Criteria } \\
\text { Standards }\end{array}$ \\
\hline Evaluative outcomes & $\begin{array}{l}\text { Are the statements summarized to produce an overall judgment? } \\
\text { Do the recommendations concern only the program evaluated? }\end{array}$ \\
\hline
\end{tabular}

The limits of our study lie in the fact that although the reports analyzed have the advantage of being almost uniform in content, this choice presents a bias because it does not promote an exhaustive representation of evaluation practice. Also, the reports, which are written accounts of the evaluation, do not present all of the choices related to the evaluation and how the evaluation was conducted. This limitation particularly affects the analysis of judgments and their basis, which is therefore based on what is written in the report rather than on the actual perception of the clients of the evaluation, which could only be perceived by conducting interviews.

\section{RESUlts}

To meet the objective of our article, which is to verify the application of the evaluation process model as defined by Hurteau, Houle (2006) (Table I), we will follow the following order: a)-Program description; b)Evaluation problem; c)-Operationalization of the evaluation; d)-Strategic choices; e)-Judgment and its foundations.

\section{A. Program Description:}

The results for the first component of the modeling, Program Description, which refers to the

The results for the first modeling component, Program Description, which refers to the aspects that need to be documented to ensure that a program is present, are presented in Table II. 
TABLE II. TABLE 2: CONTENT ANALYSIS OF THE PROGRAM DESCRIPTION

\begin{tabular}{|l|l|l|l|}
\hline \multicolumn{1}{|c|}{ Program description } & \multicolumn{1}{|c|}{ Report (1) } & \multicolumn{1}{c|}{ Report (2) } & Report (3) \\
\hline The program's target population & Yes & Yes & Yes \\
\hline Program objectives & Yes & Yes & Yes \\
\hline The characteristics of the intervention & Yes & Yes & Not in an explicit way \\
\hline $\begin{array}{l}\text { The theoretical framework of the } \\
\text { intervention. }\end{array}$ & Yes & \\
\hline
\end{tabular}

According to these results, the target population for which the program is intended, the program objectives, and the characteristics of the intervention are listed within all three reports analyzed. However, the theoretical framework of the intervention is not explicitly mentioned in the report (3).

\section{B. Evaluation Issue:}

The results for the second component of the model, the evaluation issue, are as follows (Table III)

TABLE III. CONTENT ANALYSIS OF THE EVALUATION ISSUE

\begin{tabular}{|l|l|l|l|}
\hline \multicolumn{1}{|c|}{ Evaluation Issue } & \multicolumn{1}{|c|}{ Report (1) } & \multicolumn{1}{|c|}{ Report (2) } & \multicolumn{1}{c|}{ Report (3) } \\
\hline Evaluation trigger & $\begin{array}{l}\text { Yes, explicitly or } \\
\text { implicitly }\end{array}$ & $\begin{array}{l}\text { Yes, explicitly or } \\
\text { implicitly }\end{array}$ & $\begin{array}{l}\text { Yes, explicitly } \\
\text { implicitly }\end{array}$ \\
\hline $\begin{array}{l}\text { The type of judgment expected by } \\
\text { beneficiaries }\end{array}$ & Yes & Yes & No \\
\hline $\begin{array}{l}\text { The type of justification expected by the } \\
\text { beneficiaries }\end{array}$ & No & No & No \\
\hline
\end{tabular}

Based on these findings, the trigger for the evaluation process (e.g., evaluation policy, the problem encountered, need for information, etc.), is specified in the three reports.

\section{Evaluation Implementation}

The results for the third component of the model, operationalization of evaluation, which translates the needs identified in the evaluation problem into the language of program evaluation, are presented in Table IV.

TABLE IV. CONTENT ANALYSIS OF THE IMPLEMENTATION OF EVALUATION

\begin{tabular}{|l|l|l|l|}
\hline \multicolumn{1}{|c|}{ Evaluation Implementation } & \multicolumn{1}{|c|}{ Report (1) } & \multicolumn{1}{|c|}{ Report (2) } & Report (3) \\
\hline Evaluation questions and/or objectives & Yes & Yes & Yes \\
\hline $\begin{array}{l}\text { The types of evaluation (Respecting the } \\
\text { typology of Rossi, Lipsey, Freeman } \\
(2004))\end{array}$ & Yes & Yes & Not explicitly \\
\hline $\begin{array}{l}\text { Respect for the type of judgment expected } \\
\text { by the client }\end{array}$ & Lack of information & Lack of information & Lack of information \\
\hline
\end{tabular}

\section{D. $\quad$ Strategic choices}

The results for the fourth component of the modeling, the strategic choices that establish the criteria and standards on which the judgment will be based, are presented in Table V. 
TABLE V. CONTENT ANALYSIS OF STRATEGIC CHOICES

\begin{tabular}{|l|l|l|l|}
\hline \multicolumn{1}{|c|}{ Strategic choices } & Report (1) & Report (2) & Report (3) \\
\hline The criteria & Yes, explicitly or implicitly & Yes, explicitly or implicitly & Yes, explicitly or implicitly \\
\hline The standards & Yes, explicitly or implicitly & Yes, explicitly or implicitly & Yes, explicitly or implicitly \\
\hline
\end{tabular}

According to these outcomes, in all the evaluation reports we can identify the evaluation criteria and standards.

\section{E. Evaluative conclusions:}

The findings on substantiated judgment are of particular importance because they are the raison d'etre of any program evaluation (table VI).

TABLE VI. CONTENT ANALYSIS OF EVALUATIVE FINDINGS

\begin{tabular}{|l|l|l|l|}
\hline \multicolumn{1}{|c|}{ Evaluative Conclusions } & \multicolumn{1}{|c|}{ Report (1) } & \multicolumn{1}{|c|}{ Report (2) } & Yes \\
\hline $\begin{array}{l}\text { Are the statements synthesized to } \\
\text { produce an overall judgment? }\end{array}$ & Yes & Yes \\
\hline $\begin{array}{l}\text { Is how this synthesis is done } \\
\text { documented? }\end{array}$ & Yes & Yes & No \\
\hline $\begin{array}{l}\text { Our recommendations for } \\
\text { programming made? }\end{array}$ & Yes & No & No \\
\hline $\begin{array}{l}\text { Do the recommendations relate } \\
\text { only to the program being } \\
\text { evaluated? }\end{array}$ & No & No \\
\hline
\end{tabular}

These outcomes illustrate those statements are systematically synthesized and in two of the three reports studied, this synthesis is documented. As for recommendations, only report (1) made any.

\section{CONCLUSION AND SUMMARY :}

This analysis shows that the components of the process model specific to program evaluation are not found in a homogeneous proportion within the reports studied:

- The first component, related to the description of the program, is found in all the reports studied;

- The second component, which deals with the issue of evaluation, is found more in the report (1) and not in the other reports;

- The third component, which concerns the operationalization of the evaluation, is partially identified in the reports;

- The fourth component, related to strategic choices, is present in all three reports;

- The fifth component, which concerns the evaluative conclusions, is not found homogeneously in the different reports.

The results of our study show that the practice of modeling the evaluation process is not uniform and that it would be more optimal to develop and frame the practice of program evaluation.

As for the conceptual model of the process specific to program evaluation developed by Hurteau and Houle (2006), it has proven to be a reference framework of choice for the analysis of urban development program 
evaluations. It could eventually be taken up by other researchers for application in program evaluation specific to other sectors.

\section{REFERENCES}

[1] Aboulaaguig, A. (2015). L'évaluation des politiques publiques au Maroc Etat des lieux et perspectives. 18.

[2] Banque Mondiale. (2006). Programme «Villes sans bidonvilles » du Maroc - Rapport de l'analyse d'impact social et sur la pauvreté. http://documents1.worldbank.org/curated/en/302961468276291927/pdf/879360ESW0Whit0villes0rapport0final.pdf

[3] BASLÉ, M., JOSSELIN, J.-M., \& LE MAUX, B. (2018). Dispositifs d'évaluation des politiques publiques : Méthodes et études de cas. 63.

[4] Boulmetis, J., \& Dutwin, P. (2005). The ABCs of Evaluation : Timeless Techniques for Program and Project Managers. John Wiley \& Sons.

[5] BOUTAUD, A. (2015). L'évaluation des politiques publiques, c'est quoi exactement?

[6] Chen, H. T., \& Chen, H. (2005). Practical Program Evaluation: Assessing and Improving Planning, Implementation, and Effectiveness. SAGE.

[7] Christie, C. A. (2003). What Guides Evaluation? A Study of How Evaluation Practice Maps onto Evaluation Theory. https://onlinelibrary.wiley.com/doi/10.1002/ev.72

[8] Hurteau, M., \& Houle, S. (2006). L'évaluation de programme: Réflexion concernant la théorie de l'évaluation. https://evaluationcanada.ca/distribution/200609_hurteau_marthe_houle_sylvain.pdf

[9] Ministère de l'Habitat, de l'Urbanisme et de la Politique de la Ville. (2018). Evaluation du programme de logements sociaux à $250.000 \mathrm{DH}$ et du programme de logements à faible valeur immobilière de $140.000 \mathrm{DH}$. https://boursenews.fnh.ma/uploads/PROCHURE250.pdf

[10] Mongiat, S. (2007). Analyse des pratiques en évaluation de programme : Les éléments qui contribuent à formuler un jugement fondé. 96.

[11] ONU. (2015). The International Year of Evaluation. https://unhabitat.org/2015-international-year-of-evaluation

[12] Rossi, P. H., Lipsey, M. W., \& Freeman, H. E. (2004). Evaluation: A Systematic Approach. SAGE Publications.

[13] Sandahl, J.-E. F., Ray C. Rist, Rolf. (2002). International Atlas of Evaluation. Transaction Publishers. 